\title{
Optimal Capital Taxation with Entrepreneurial Risk
}

\author{
Vasia Panousi and Catarina Reis \\ Federal Reserve Board and Universidade Catolica Portuguesa*
}

February 15, 2012

\begin{abstract}
We examine the optimal taxation of capital in a Ramsey setting of a general-equilibrium heterogeneous-agent economy with uninsurable idiosyncratic investment or capital-income risk. We fully characterize the optimal tax in the case where there is no safe income in the economy. When the interest rate is allowed to adjust to changes in the capital tax, the optimal capital tax is always constant, even off steady state, and is positive when the variance of risk is higher than the mean return to the risky asset. When the interest rate is exogenously fixed, the optimal capital tax is zero. Therefore, general-equilibrium considerations are crucial for the dynamic effects of capital taxation when investment is risky.
\end{abstract}

\footnotetext{
*Email addresses: vasia.panousi@frb.gov, creis@ucp.pt. We would like to thank Peter Diamond and Dimitris Papanikolaou for useful comments and discussions. The views presented in this paper are solely those of the authors and do not necessarily represent those of the Board of Governors of the Federal Reserve System or its staff members.
} 


\section{Introduction}

We study optimal capital taxation in an environment where agents face uninsurable idiosyncratic investment or capital-income risk. Such risk is empirically important for all investment decision makers, whether they are entrepreneurs and private business owners or managers of publicly traded firms. In this context, capital taxation raises an interesting tradeoff: On the one hand, it comes at the usual cost, as it distorts agents' saving decisions. On the other hand, it has benefits, as it provides agents with partial insurance against idiosyncratic capital-income risk. In addition, this insurance aspect of capital taxation may even lead to higher capital accumulation in general equilibrium, contrary to what happens in models of complete markets or uninsurable labor income risk. Therefore, a positive tax on capital income could be welfare-improving, and more so than in other environments.

Our modelling framework builds on Angeletos (2007), who develops a variant of the neoclassical growth model that allows for idiosyncratic investment risk, and studies the effects of such risk on macroeconomic aggregates. Agents own privately-held businesses that operate under constant returns to scale. These private businesses are subject to idiosyncratic risk that the agents cannot diversify away. However, agents are not exposed to labor-income risk, and they can also freely borrow and lend in a riskless bond. Abstracting from borrowing constraints, labor-income risk, and other market frictions, isolates the impact of the idiosyncratic investment risk, and preserves tractability of the model. There is a government, imposing a proportional tax on capital income, along with a non-contingent lump-sum tax or transfer. The social planner maximizes ex ante welfare, namely a weighted average of agents' expected lifetime utilities, subject to all the constraints imposed by individual behavior and general equilibrium. In other words, this paper performs the optimal taxation exercise in a Ramsey framework, with exogenously given policy instruments (with the addition of lump-sum transfers to the agents).

We show that the social planner's objective consists of two terms. The first term captures the effects of the future path of capital taxes on the dynamic paths for wages, government transfers, and asset prices. The planner takes this consideration into account because it determines the net present discounted value of agents' future safe income (aka human wealth), namely of income that comes from wages or government transfers or any other sources that are not subject to idiosyncratic risk. The second term captures the difference between the risk-adjusted return to saving and the marginal propensity to consume. The risk-adjusted return to saving is the certainty-equivalent of the overall or total return to saving, which is simply a weighted average of the risky and the risk-free asset returns. Since agents are risk averse and face risk in their consumption stream through the uninsurable investment shocks they bear, the risk-adjusted return will be lower than the total return to saving. In turn, the difference between the risk-adjusted return and the marginal propensity to consume is the risk-adjusted rate of growth of individual consumption (and total wealth). Hence, the planner weighs considerations about each agent's ex ante human wealth versus considerations 
of maximizing the rate of growth of each agent's total effective wealth (the sum of human wealth plus asset holdings).

We fully characterize the optimal tax in the case where there is no safe income, i.e. for the $A k$ version of our model. We show that the optimal tax is always constant, even off the steady state. We find that, when the interest rate endogenously adjusts to clear the bond market, where the bond is a riskless asset in zero net supply, then the optimal tax maximizes the risk-adjusted growth rate of wealth (the difference between the risk-adjusted return to saving and the marginal propensity to consume), and it is equal to $1-A / \sigma^{2}$. Here, $A$ is the mean return to the risky asset (capital) and $\sigma^{2}$ is the variance of idiosyncratic capital-income risk. Hence, the optimal tax is positive when the mean return to capital, $A$, is lower than the variance of idiosyncratic risk, $\sigma^{2}$. By contrast, if the interest rate is exogenous, as in the "small open economy" version of our model, then the optimal tax is always zero.

Therefore, our analysis emphasizes two things. First, the implications for optimal taxation in an environment of investment risk crucially depend on general equilibrium considerations, namely on whether the interest rate is allowed to endogenously respond to fiscal policy changes. If that is the case, we then show that the after-tax risk-free rate is increasing in the tax in general equilibrium, which is possible here because that rate is below the discount rate in preferences, due to precautionary saving motives. This increase in the interest rate when the capital tax increases subsequently induces an increase in wealth and capital accumulation, enhancing the positive redistributional impact that the tax would in any case have on welfare, simply by equalizing consumption across different types of agents. In fact, without the adjustment of the interest rate, the optimal capital tax is always zero. This is because the direct insurance effect of the tax, which is to reduce the standard deviation of effective risk, $\sigma(1-\tau)$, is not strong enough to outweigh the usual negative effect of the tax on savings. Therefore, the general equilibrium or indirect insurance aspect of the tax, operating through the adjustment of asset prices, is needed for the emergence of the possibility of a positive optimal capital tax. Another way of putting this is to say that we have shown an impossibility theorem: There does not exist a tax that can make the optimal allocation of the closed economy also optimal for the open economy.

Second, the optimal tax in the case where the interest rate is endogenous is not unambiguously positive. This is due to agents' impatience, and the intuition is similar to that under complete markets. In complete markets, the tax that maximizes steady state consumption is actually negative, but agents are too impatient to sacrifice consumption today for the benefit of increased consumption in the future at the golden rule steady state. As a result, the capital tax that maximizes ex ante (as opposed to steady state) welfare is zero. In our environment, if we are in the area where the tax increases the aggregates, this might end up being too costly for impatient agents, thereby leading to optimality of a negative tax. However, this only occurs when risk is very low, and the relevant condition is very unlikely to be satisfied in the data. 
Overall, our analysis shows that, for purposes of optimal capital taxation, it is very important to take into account the dynamic general equilibrium effects of capital taxation on asset prices. These considerations cannot be captured by, for example, traditional public finance partial equilibrium models or two-period macro models. This is especially problematic for issues of capital accumulation under investment risk, that being by its nature a dynamic problem.

The present paper is related to those by Angeletos (2007) and Panousi (2012). Our framework builds on Angeletos (2007), who examines the effects of idiosyncratic investment risk for steady state aggregates. Panousi (2012) examines the effects of capital taxation on aggregates and welfare, in a similar framework, but without solving for the full optimal taxation problem. She finds that capital taxation might increase capital accumulation in steady state.

\section{Related Literature}

We focus on an environment with idiosyncratic investment risk, because such risk is in fact empirically relevant, even in a financially developed country like the United States. First, Moskowitz and Vissing-Jorgensen (2002), among others, find that about 80 percent of all private equity is owned by agents who are actively involved in the management of their own firm, and for whom such investment constitutes at least half of their total net worth. It seems plausible, then, that entrepreneurial risk must be even more prevalent in less developed economies. Second, Panousi and Papanikolaou (2011) show that the negative relationship between idiosyncratic risk and the investment of publicly-traded firms in the United States is stronger in firms where the mangers hold a larger fraction of the firm's shares. Combined, these findings strengthen the empirical applicability of our model setup, because they demonstrate that a large fraction of total investment in the United States is sensitive to idiosyncratic risk, essentially through the risk aversion of the agents making the investment decisions.

This paper relates to the macroeconomic literature on optimal taxation. Most of this literature has focused either on complete markets or on incomplete markets with labor-income risk. Starting with the Ramsey literature of exogenously given market structure and exogenous policy instruments, Chamley (1986), Judd (1985), and Atkeson, Chari and Kehoe (1999) establish the result of zero optimal capital taxation when markets are complete. Correia (1996) shows that, in the neoclassical model, if there are restrictions on the taxation of production factors, then the tax rate on capital income in steady state is different from zero. Aiyagari (1995) extends the complete-markets framework to include uninsurable labor-income risk and borrowing constraints, and finds that the optimal capital tax is positive in the long run 11 Contrary to Aiyagari (1994), where precautionary saving leads to over-accumulation of capital in steady state, compared to complete markets, we show that capital at the optimum steady state will be below the complete markets level. Chamley

\footnotetext{
${ }^{1}$ A related but different normative exercise to that in Aiyagari (1995) is conducted by Davila, Hung, Krusell and Rios-Rull (2005), in the spirit of Geanakoplos-Polemarchakis.
} 
(2003) argues that it might be best to think of the reasoning behind Aiyagari's positive optimal capital tax result as related to the ex-ante insurance or ex-post redistribution aspect of the tax: the planner taxes agents with high income realizations, and subsidizes agents with low income realizations, thereby equalizing consumption across different types of agents. Our paper completes the literature on optimal taxation in the Ramsey tradition and shows that, when markets are incomplete due to the presence of uninsurable capital-income risk, then the optimal capital tax will be different from zero, and will be positive or negative depending on insurance considerations like those pointed out in Chamley (2003).

Moving to the Mirrlees literature of endogenous market incompleteness and endogenous policy instruments, Albanesi (2006) considers optimal taxation in a two-period model of entrepreneurial activity in a constrained-efficiency setting. Shourideh (2012) also studies the optimal taxation of entrepreneurial income. In his model, though the intertemporal wedge determining the tax on wealth cannot be unambiguously signed, the incentive constraint seems to create a force towards a wealth subsidy, since increasing capital tends to loosen the incentive compatibility constraint in the future. In general, however, the extensive theoretical work on taxation originating from the Mirrlees tradition focuses on labor-income risk. This literature shows that, if insurance is limited due to the presence of asymmetric information, then it may be best to restrict free access to savings. This result has in turn been interpreted as a justification for capital taxation. Some additional examples include Diamond and Mirrlees (1978), Golosov, Kocherlakota, and Tsyvinski (2003), Kocherlakota, (2005), Albanesi and Sleet (2006), Golosov, Troshkin, Tsyvinsky and Weinzierl (2010), and Werning (2011). Farhi and Werning (2008) study optimal nonlinear taxation of labor and capital in a political economy model with heterogeneous agents, where policies are chosen sequentially over time, without commitment, as the outcome of democratic elections. They find that credible policies show a concern for future inequality and that capital taxation emerges as an efficient redistributive tool for this purpose.

The overlapping-generations literature has often found support for positive optimal capital taxation. Conesa, Kitao and Krueger (2009) quantitatively characterize the optimal capital and labor income taxes in an overlapping generations model with idiosyncratic uninsurable income shocks and permanent productivity differences across households. They find that the optimal capitalincome tax rate is significantly positive at 36 percent, mainly driven by the life-cycle structure of the model $2^{2}$ Erosa and Gervais (2002), in an overlapping-generations economy where agents' productivity varies over time, find that positive capital taxes may be optimal when labor taxes cannot be conditioned on age. Garriga (2003), and Peterman (2011) also find similar results.

A strand of the public finance literature has examined the effects of capital taxation on risk taking, mostly in a partial equilibrium framework. Some examples include Domar and Musgrave

\footnotetext{
${ }^{2}$ Domeij and Heathcote (2004) perform a similar exercise. Uhlig and Yanagawa (1996) show that higher capital income taxes lead to faster growth in an overlapping generations economy with endogeneous growth.
} 
(1944), Stiglitz (1969), Ahsan (1974), Sandmo (1977), and Kanbur (1981). Our paper is also related to Varian (1980), who assumes that differences in observed income are due to exogenous differences in luck. In a two-period model of endogenous saving, he finds that the optimal capital-income tax is positive due to the trade-off it involves between the distortion in the saving decision and the provision of social insurance through redistribution. Finally, Angeletos and Panousi (2011) use a model similar to the one in the present paper to examine the effects of government consumption on steady state aggregates, for the case where government spending is financed solely through lump-sum taxes.

\section{Benchmark model}

Time is continuous and indexed by $t \in[0, \infty)$. There is a continuum of agents distributed uniformly over $[0,1]$.

\subsection{Households and preferences}

All agents are endowed with one unit of time. Preferences are logarithmic over consumption, $c$, i.e. $U_{t}=E_{t} \int_{t}^{\infty} e^{-\beta s} U\left(c_{s}\right) d s$, where $\beta>0$ is the discount rate and $U(c)=\ln (c)$.

\subsection{Firms and idiosyncratic risk}

An entrepreneur owns and runs a firm operating a production function $F(k)=A k$, where $k$ is capital input. The entrepreneur can invest only in the capital of his own firm. This capital investment in his firm is subject to idiosyncratic uninsurable risk. The idiosyncratic shocks are i.i.d., and hence there is no aggregate uncertainty. An entrepreneur can also save in a riskless bond, $b$. Agents do not receive wage or transfer income.

The financial wealth of an entrepreneur $i$, denoted by $x_{t}^{i}$, is the sum of his holdings in private capital, $k_{t}^{i}$, and in the riskless bond, $b_{t}^{i}$, i.e. $x_{t}^{i}=k_{t}^{i}+b_{t}^{i}$. The evolution of $x_{t}^{i}$ is:

$$
d x_{t}^{i}=\left(1-\tau_{t}\right) d \pi_{t}^{i}+\left[\left(1-\tau_{t}\right) R_{t} b_{t}^{i}-c_{t}^{i}\right] d t
$$

where $d \pi_{t}^{i}$ are the firm's profits (capital income), $R_{t}$ is the interest rate on the riskless bond, $\tau_{t}$ is

the proportional capital-income tax, and $c_{t}^{i}$ is consumption. A no-Ponzi-game condition is imposed, ensuring the non-negativity of consumption.

Firm profits are given by:

$$
d \pi_{t}^{i}=\left[A k_{t}^{i}-\delta k_{t}^{i}\right] d t+\sigma k_{t}^{i} d z_{t}^{i}
$$

where $F(k)=A k$ is the production function, $A$ is the marginal product of capital, and $\delta$ is the mean depreciation rate in the aggregate economy. Idiosyncratic risk is introduced through $d z_{t}^{i}$, a 
standard Wiener process that is i.i.d. across agents and across time. Literally taken, $d z_{t}^{i}$ represents a stochastic depreciation shock. However, these shocks can also be modelled or interpreted as stochastic productivity shocks. The scalar $\sigma$ measures the amount of undiversified idiosyncratic risk, and it is an index of market incompleteness, with higher $\sigma$ corresponding to a lower degree of risk-sharing, and with $\sigma=0$ corresponding to complete markets.

\subsection{Government}

At each point in time the government taxes capital income and bond income at the rate $\tau_{t}$. Part of the tax revenue is used by the government for own consumption at the deterministic rate $G_{t}$. This government spending does not affect the utility from private consumption or the production technology. The government budget constraint is:

$$
d B_{t}^{g}=\left[\tau_{t}(A-\delta) \int_{i} k_{t}^{i}+\tau_{t} R_{t} B_{t}^{g}-G_{t}\right] d t
$$

where $B_{t}^{g}$ denotes the level of government assets (i.e. minus the level of government debt). A no-Ponzi game condition is imposed to rule out explosive debt accumulation.

\section{Equilibrium}

This section characterizes individual behavior and the general equilibrium in the economy. The initial position of the economy is given by the distribution of $\left(k_{0}^{i}, b_{0}^{i}\right)$ across households. An equilibrium is a deterministic sequence of prices $\left\{R_{t}\right\}_{t \in[0, \infty)}$, a deterministic sequence of policies $\left\{\tau_{t}, G_{t}\right\}_{t \in[0, \infty)}$, a deterministic macroeconomic path $\left\{C_{t}, K_{t}, Y_{t}, X_{t}\right\}_{t \in[0, \infty)}$, and a collection of individual contingent plans $\left(\left\{c_{t}^{i}, k_{t}^{i}, b_{t}^{i}, x_{t}^{i}\right\}_{t \in[0, \infty)}\right)$ for $i \in[0,1]$, such that the following conditions hold: (i) given the sequences of prices and policies, the plans are optimal for the households; (ii) the bond market clears, $\int_{t} b_{t}^{i}=0$, in all $t$; (iii) the government budget constraint $(3)$ is satisfied in all $t$; and (iv) the aggregates are consistent with individual behavior, $C_{t}=\int_{i} c_{t}^{i}, K_{t}=\int_{i} k_{t}^{i}, Y_{t}=\int_{i} F\left(k_{t}^{i}\right)=A \int_{i} k_{t}^{i}$, $X_{t}=\int_{i} x_{t}^{i}$, in all $t$.

\subsection{Individual behavior}

Agents' production function, $F$, exhibits constant returns to scale, and hence optimal profits are linear in own capital:

$$
d \pi_{t}^{i}=r k_{t}^{i} d t+\sigma k_{t}^{i} d z_{t}^{i}
$$

where $r \equiv A-\delta$. Here, $r$ is an entrepreneur's expectation of the net return to his capital prior to the realization of his idiosyncratic shock, as well as the mean of the realized returns in the cross-section of firms, since there is no aggregate uncertainty. As in Angeletos (2007), the key result here is that 
entrepreneurs face linear, albeit risky, returns to their investment.

The evolution of financial wealth for an entrepreneur is described by:

$$
d x_{t}^{i}=\left[\left(1-\tau_{t}\right) r k_{t}^{i}+\left(1-\tau_{t}\right) R_{t} b_{t}^{i}-c_{t}^{i}\right] d t+\sigma\left(1-\tau_{t}\right) k_{t}^{i} d z_{t}^{i}
$$

The first term captures the expected rate of growth of wealth, and it shows that wealth grows when saving exceeds consumption expenditures. The second term captures the effect of idiosyncratic risk.

Because of the homotheticity of the preferences and the linearity of the budget constraint (5) in assets, the optimal individual policy rules will be linear in wealth, $x_{t}^{i}$. Hence, for given prices and policies, an agent's consumption-saving problem reduces to a tractable homothetic problem as in Samuelson's and Merton's classic portfolio analysis. The following Lemma then characterizes optimal individual behavior.

Lemma 1. Let $\left\{R_{t}\right\}_{t \in[0, \infty)}$ and $\left\{\tau_{t}, G_{t}\right\}_{t \in[0, \infty)}$ be equilibrium price and policy sequences. Then, equilibrium consumption, capital and bond holdings for household $i$ are given by $c_{t}^{i}=m_{t} x_{t}^{i}, k_{t}^{i}=$ $\phi_{t} x_{t}^{i}$, and $b_{t}^{i}=\left(1-\phi_{t}\right) x_{t}^{i}$, where $m_{t}$ is the marginal propensity to consume out of wealth, and $\phi_{t}$ is the fraction of wealth invested in capital. In addition, $m_{t}$ and $\phi_{t}$ are given by:

$$
\text { (i) } m_{t}=\beta \text { for all } t \quad \text { and } \quad(\text { ii }) \phi_{t}=\frac{\left(1-\tau_{t}\right) r-\left(1-\tau_{t}\right) R_{t}}{\sigma^{2}\left(1-\tau_{t}\right)^{2}}
$$

Condition (6j) is essential the Euler condition: With logarithmic preferences and liner budget, the marginal propensity to consume is constant over time, and equal to the discount rate in preferences. In other words, the income and substitution effect on consumption from a change in the saving return exactly cancel out with logarithmic preferences. Condition (6ji) simply says that the fraction of wealth invested in the risky asset is increasing in the risk premium, $\mu_{t}=\left(1-\tau_{t}\right) r-\left(1-\tau_{t}\right) R_{t}$, and decreasing in the effective variance of risk, $\sigma^{2}\left(1-\tau_{t}\right)^{2}$.

Using (5) and Lemma (1), we get the following characterization for individual consumption dynamics.

Lemma 2. The evolution of individual consumption, investment, and wealth is characterized by:

$$
\frac{d c_{t}^{i}}{c_{t}^{i}}=\frac{d x_{t}^{i}}{x_{t}^{i}}=\left(\rho_{t}-\beta\right) d t+\sigma\left(1-\tau_{t}\right) \phi_{t} d z_{t}^{i}
$$

where $\rho_{t}=\left(1-\tau_{t}\right) \phi_{t} r+\left(1-\tau_{t}\right)\left(1-\phi_{t}\right) R_{t}$ is the mean portfolio return or mean return to saving. Solving for $c_{t}^{i}$, we get:

$$
c_{t}^{i}=c_{0}^{i} \cdot \exp \left[\int_{0}^{t}\left(\hat{\rho}_{t}-\beta\right) d s+\int_{0}^{t} \sigma\left(1-\tau_{s}\right) \phi_{s} d z_{s}^{i}\right]
$$

where $\hat{\rho}_{t}=\rho_{t}-\frac{1}{2} \sigma^{2}\left(1-\tau_{s}\right)^{2} \phi_{t}^{2}=\left(1-\tau_{t}\right) \phi_{t} r+\left(1-\tau_{t}\right)\left(1-\phi_{t}\right) R_{t}-\frac{1}{2} \sigma^{2}\left(1-\tau_{s}\right)^{2} \phi_{t}^{2}$ is the risk-adjusted 
return to saving.

The fact that investment is subject to undiversifiable idiosyncratic risk introduces a wage between the marginal product of capital and the risk-free rate, so that $R_{t}<\rho_{t}<r$. Since agents face risk in their consumption stream, stemming from the risk in their private businesses, they have a precautionary saving motive, represented by the term $\frac{1}{2} \sigma^{2}\left(1-\tau_{s}\right)^{2} \phi_{t}^{2}$ in the risk-adjusted return to saving, so that $\hat{\rho}_{t}<\rho_{t}$. From this and (7), it follows that, if $\hat{\rho}_{t}>\beta$, then individual wealth and consumption grow at a positive rate.

\subsection{General equilibrium}

At any point in time, the aggregates do not depend on the extend of wealth inequality, because individual consumption and investment are linear in individual wealth. Aggregating the policy rules across agents and imposing market-clearing for the risk-free bond, we arrive at the following characterization of the general equilibrium.

Lemma 3. In equilibrium, the aggregate dynamics satisfy the following system:

$$
\begin{gathered}
d K_{t}=\left[A K_{t}-\delta K_{t}-C_{t}-G_{t}\right] d t \\
m_{t}=\beta \\
0=\left(1-\phi_{t}\right) K_{t}
\end{gathered}
$$

Condition (9) is the aggregate resource constraint of the economy. It follows from aggregating budgets and policies across all households, using the government budget constraint, bond market clearing $B_{t}=0$, and $r=A-\delta$. Condition (10) is the Euler equation for logarithmic preferences. Condition (11) represents bond market clearing. It follows from aggregating bond holdings across agents and using the fact that the bond is in zero net supply. This condition holds for all values of the capital stock if and only if $\phi_{t}=1$. In other words, $\phi_{t}=1$ is essentially the condition that guarantees bond market clearing in the closed economy. Using (6ii), this implies that in the equilibrium of the closed economy:

$$
R_{t}=r-\sigma^{2}\left(1-\tau_{t}\right)
$$

In other words, there is a positive relationship between the interest rate and the capital-income tax. The intuition behind this positive relationship stems from the general equilibrium insurance aspect of the capital tax. In particular, when the tax increases, the effective variance of risk, $\sigma\left(1-\tau_{t}\right)$, falls. This reduces the demand for precautionary saving, and leads to an increase in the interest rate in general equilibrium. Put differently, since agents are faced with a lower variance of risk when the tax increases, they will require a higher interest rate for the same amount of saving. Hence, the interest rate is increasing in the tax in general equilibrium. 


\section{The planner's problem}

The social planner's objective is to choose the capital-income tax that maximizes ex ante expected utility, subject to the conditions for individual optimization and general equilibrium in section (4).

The planner's objective function is the ex ante expected utility across agents, i.e. a weighted sum of agents' value functions, where the weights depend on the asset holding of each agent as a fraction of aggregate asset holdings:

$$
\max _{\left\{\tau_{t}\right\}_{t=0}^{\infty}} \int_{i} V\left(x_{0}^{i} ; \tau_{t}\right) p\left(x_{0}^{i} ; \tau_{t}\right) d x_{0}^{i}
$$

Here, $\int_{i} \equiv E_{-1}$ for the ex ante welfare calculation across agents. The value function for an agent with initial wealth $x_{0}^{i}$ at $t=0$, given the tax sequence $\left\{\tau_{t}\right\}_{t=0}^{\infty}$, is the solution to the problem $V\left(x_{0}^{i} ;\left\{\tau_{t}\right\}_{t=0}^{\infty}\right)=\max _{c^{i}, \phi^{i}} E_{0} \int_{0}^{\infty} e^{-\beta t} \ln \left(c_{t}^{i}\right) d t$, subject to constraint (5). The weight used for an agent of wealth $x_{0}^{i}$ is $p\left(x_{0}^{i} ; \tau_{t}\right)$. Without loss of generality, we assume that at $t=0$ the wealth distribution is concentrated at one point, so that all agents hold the same amount of capital, equal to the economy-wide aggregate capital stock, and therefore receive the same weight in the planner's objective, $p\left(x_{0}^{i} ; \tau_{t}\right)=1$.

When maximizing his objective, the planner has to take into account the constraints from section (4). These constraints are as follows. First, equation (8) describing the evolution of individual consumption. This equation incorporates the conditions for individual optimization from Lemma (1). From (8), or equivalently from (7), the resource constraint of the economy follows by aggregation. Second, bond market clearing captured by $\phi_{t}=1$ or $b_{t}^{i}=0$ for all $i$. Third, the government budget constraint (3). Using these constraints, the planner maximizes 13 with respect to $\left\{\tau_{t}\right\}_{t=0}^{\infty} !^{3}$ The following proposition characterizes the planner's problem.

Proposition 1. The social planner chooses the capital income tax so as to solve the following problem:

$$
\begin{gathered}
\max _{\left\{\tau_{t}\right\}_{t=0}^{\infty}} \int_{i} V\left(k_{0}^{i} ; \tau_{t}\right) d k_{0}^{i} \quad \text { s.t. } \\
V\left(k_{0}^{i} ;\left\{\tau_{t}\right\}_{t=0}^{\infty}\right)=\int_{0}^{\infty} e^{-\beta t}\left\{\ln J\left(\left\{\tau_{s}\right\}_{s=0}^{\infty}\right)+\int_{0}^{\infty} g\left(\tau_{s}, \phi_{s}\left(\tau_{s}\right), R_{s}\left(\tau_{s}\right)\right) d s\right\} d t \\
G_{t}=\tau_{t}(A-\delta) K_{t} \\
\phi_{t}=1
\end{gathered}
$$

where $J \equiv J\left(\left\{\tau_{t}\right\}_{t=0}^{\infty}\right)=c_{0}^{i}=\beta k_{0}^{i}$, and $g\left(\tau_{s}, \phi_{s}\left(\tau_{s}\right), R_{s}\left(\tau_{s}\right)\right)=\hat{\rho}_{t}-\beta$.

We will now set aside conditions (16) and (17) for a moment. From (15), the value function consists of two parts. The first part, reflected in the term $J(\cdot)$, captures the fact that time-zero

\footnotetext{
${ }^{3}$ The planner's preferences could be modified to include utility from government spending, $G_{t}$.
} 
consumption depends on the entire sequence of optimal tax rates in the future. The second part, reflected in the term $g(\cdot)$, shows that the value function is increasing in $g$, i.e. it is increasing in the difference between the risk-adjusted return to saving and the marginal propensity to consume. Since the planner's objective is increasing in $V(\cdot)$, it follows that the optimal tax should solve the following first order condition:

$$
\frac{d V}{d \tau_{s}}=\frac{d V}{d J} \frac{d J}{d \tau_{s}}+\frac{d V}{d g_{s}} \frac{d g_{s}}{d \tau_{s}}
$$

subject to the constraints in proposition 1. Here, $d V / d J=\int_{0}^{\infty} e^{-\beta t} d t / J=1 /(\beta J)>0$, and $d V / d g_{s}=\int_{s}^{\infty} e^{-\beta t} d t=\beta^{-1} e^{-\beta s}>0$. The crucial terms in 18 are then $d J / d \tau_{s}$ and $d g_{s} / d \tau_{s}$. We will now examine each one of them in turn.

In general, when there are sources of safe income in the economy, such as wage income or transfer income, total effective wealth, $w_{t}^{i}$, for an agent will be the sum of financial wealth, $x_{t}^{i}$, and safe wealth, $h_{t}^{i}$, so that $c_{0}^{i}=\beta w_{0}^{i}=\beta\left(x_{0}^{i}+h_{0}^{i}\right)$. In that case, $h_{0}^{i}$ is the present discounted value of wage and transfer income, and as such it depends on the entire dynamic path for the tax, directly as well as indirectly, through the effects of the tax on the aggregate capital stock and the interest rate. These effects are captured in the term $d J / d \tau_{s}$.

In addition, when there are sources of safe income, then $\phi_{t}=K_{t} / W_{t}=K_{t} /\left(K_{t}+H_{t}\right)<1$, and therefore the total effect of the tax on $g$, i.e. on the difference between the risk-adjusted return to saving and the marginal propensity to consume, is:

$$
\frac{d g_{s}}{d \tau_{s}}=\frac{\partial g_{s}}{\partial \tau_{s}}+\frac{\partial g_{s}}{\partial \phi_{s}} \frac{\partial \phi_{s}}{\partial \tau_{s}}+\frac{\partial g_{s}}{\partial R_{s}} \frac{\partial R_{s}}{\partial \tau_{s}}=-R_{s}+\left(1-\tau_{s}\right)\left(1-\phi_{s}\right) \frac{d R_{s}}{d \tau_{s}}
$$

where $\partial g_{s} / \partial \tau_{s}=-R_{s}, \partial g_{s} / \partial \phi_{s}=0, \partial g_{s} / \partial R_{s}=\left(1-\tau_{s}\right)\left(1-\phi_{s}\right)$, using the formula for optimal portfolio allocation from (6). In other words, the total effect of the tax on $g$ consists of a direct part, $\partial g_{s} / \partial \tau_{s}$, and an indirect part, capturing the effects of the tax on the risk-adjusted return to saving through portfolio reallocation, $\partial g_{s} / \partial \phi_{s} \cdot \partial \phi_{s} / \partial \tau_{s}$, and interest-rate adjustment, $\partial g_{s} / \partial R_{s} \cdot \partial R_{s} / \partial \tau_{s}$. The direct effect of the tax on $g$ is unambiguously negative and it captures the fact that an increase in the tax reduces the mean return to saving. The first term in the indirect effect of the tax is zero from the envelope condition, because the optimal choice of $\phi_{t}$ maximizes the risk-adjusted return to saving, $\hat{\rho}_{t}$. The second term in the indirect effect of the tax captures the effect of the tax on the interest rate, and through that on portfolio reallocation, saving return, and $g$. The appendix shows that $\partial R_{t} / \partial \tau_{t}>0$, even when $\phi_{t}<1$ (equation 12 demonstrates this for the case of $\phi_{t}=1$ ): An increase in the tax reduces the effective variance of risk and hence the demand for precautionary saving, and leads to an increase in the interest rate. This increase in the interest rate makes the bond more attractive, and tends to reduce investment in the risky asset, which has a higher mean return. Intuitively, the effect of this on the return to saving will be smaller, if $\phi_{t}$ was small to begin with. Or, the increase in the interest rate will affect the return to saving, and therefore $g$, more, when $1-\phi_{t}$ is higher. 
In the present model specification, we have eliminated sources of safe income such as wages and transfers. Therefore, one immediate simplification is that, since $c_{0}^{i}=\beta x_{0}^{i}=\beta k_{0}^{i}$ and $k_{0}^{i}$ is exogenously given, $d J / d \tau_{s}=0$. Furthermore, since $b_{t}^{i}=0$ for all $i$ and $t$, or since $\phi_{t}=1$, we also have that $\partial g_{s} / \partial \tau_{s}=-R_{s}$. Using this discussion, proposition 1, and equation (12), the following lemma summarizes the case of the economy with no safe income.

Lemma 4. When all income is risky, the optimal capital-income tax solves:

$$
\frac{d g_{s}}{d \tau_{s}}=-R_{s}=-\left[r-\sigma^{2}\left(1-\tau_{t}\right)\right]=0
$$

subject to the government budget constraint (16). Furthermore:

(i) In the small open economy version of the model, the optimal tax is zero, i.e. $\tau^{\text {opt }}=0$.

(ii) In the closed economy version of the model, the optimal tax is $\tau^{o p t}=1-\frac{r}{\sigma^{2}}$. The optimal tax is nonzero, it is positive when the variance of risk is sufficiently high compared to the mean return of the risky asset $\left(\sigma^{2}>r\right)$, and it is constant over time.

Lemma (4) shows that, when all income is risky, the optimal capital tax simply maximizes $g$, namely it maximizes the difference between the risk-adjusted return to saving, $\hat{\rho}_{t}$ and the marginal propensity to consume, $\beta$. Part (i) of the lemma follows immediately form $(20)$, for $R_{s}=R$ for all $s$, exogenously given: there is no interior optimum and the planner's objective is negative, which means that the optimal tax is zero. Hence, in the open economy, the direct insurance provision of the tax, i.e. the fact that the tax reduces the effective variance of risk, $\sigma\left(1-\tau_{t}\right)$, is not strong enough to outweigh the distortion the tax creates on investment. From part (ii) of the lemma, substituting the formula for the optimal tax into the bond-market-clearing condition (12), we get that $R_{t}=0$ in the closed economy equilibrium with the optimal tax. In other words, the interest rate in the closed economy adjusts in such a way, that no agent wants to hold the safe asset in equilibrium. This ensures that there is really no safe income in this economy. The optimal tax also has to satisfy $(16)$, so that optimal government spending is given by $G_{t}^{o p t}=\left(1-\frac{r}{\sigma^{2}}\right) r K_{t}$.

Lemma (4), as well as equation (19), demonstrate that our result about a positive optimal capital income tax hinges on general equilibrium effects of the tax on the interest rate, and subsequently on the portfolio reallocation and the return to saving, which are absent in the open economy. Put differently, the result that the optimal capital tax is positive does not hinge on our assumption that the tax system provides full loss offset (a direct insurance effect of the tax): In the open economy, the tax still provides full loss offset, but this effect is not strong enough to outdo the standard distortionary effect of the tax on savings. By contrast, in the closed economy, it is the general-equilibrium effect of the tax through the interest rate that generates additional or indirect insurance provision and therefore makes a positive tax optimal.

The result that the optimal capital-income tax is positive in our framework is reminiscent of Varian (1980). Varian examines the optimal consumption-saving problem in a two-period model 
with exogenously risky income (luck). He finds that the optimal marginal tax rate in a linear capitalincome system is between 0 and 1 . This is because, as income contains a random component, a system of redistributive taxation contributes to reducing the variance of after-tax income. This benefit from social insurance might outweigh the distortionary effect of the tax on saving, leading to a positive optimal capital-income tax. Our $A k$ framework also essentially takes income as exogenously risky, and generalizes Varian's result into an infinite horizon setting. It is generally acknowledged that taxation results derived in a two-period model do not necessarily carry through in the infinite-horizon version of that model. However here, it turns out that Varian's two-period result does in fact hold when the horizon is infinite: The optimal capital-income tax in an economy with exogenously risky income (and no source of safe income) is positive. Nonetheless, our paper actually corrects the intuition in Varian. We show that the optimality of the positive capital tax is not due to the direct redistributional effect of the tax, as Varian concludes, but to the indirect or general equilibrium insurance effect of the tax, operating through the adjustment of the interest rate to clear the bond market.

\section{Conclusions}

We examine the optimal taxation of capital in a Ramsey setting of a general-equilibrium heterogeneousagent economy with uninsurable idiosyncratic investment or capital-income risk. We fully characterize the optimal tax in the case where there is no safe income in the economy. When the interest rate is allowed to adjust to changes in the capital tax, the optimal capital tax is always constant, even off steady state, and is positive when the variance of risk is higher than the mean return to the risky asset. When the interest rate is exogenously fixed, the optimal capital tax is zero.

Therefore, general-equilibrium considerations of asset-price adjustments are crucial for the dynamic effects of capital taxation when investment is risky. When the interest rate can adjust to changes in the capital tax, we show that the after-tax risk-free rate is increasing in the tax in general equilibrium. This increase in the interest rate when the capital tax increases subsequently induces an increase in wealth and capital accumulation, enhancing the positive redistributional impact that the tax would in any case have on welfare, simply by equalizing consumption across different types of agents. In fact, without the adjustment of the interest rate, the optimal capital tax is always zero. This is because the direct insurance effect of the tax, which is to reduce the standard deviation of effective risk, $\sigma(1-\tau)$, is not strong enough to outweigh the usual negative effect of the tax on savings. Therefore, the general equilibrium or indirect insurance aspect of the tax, operating through the adjustment of asset prices, is needed for the emergence of the possibility of a positive optimal capital tax. 


\section{References}

Ahsan, S.M., 1976. Taxation in a two-period temporal model of consumption and portfolio allocation. Journal of Public Economics 5, 337-352.

Aiyagari, S.R., 1994. Uninsured idiosyncratic risk and aggregate saving. Quarterly Journal of Economics 109, 659-684.

Aiyagari, S.R., 1995. Optimal capital income taxation with incomplete markets, borrowing constraints, and constant discounting. Journal of Political Economy 103, 1158-1175.

Albanesi, S., 2006. Optimal taxation of entrepreneurial capital with private information. NBER Working Paper 12419.

Angeletos, G.-M., 2007. Uninsured idiosyncratic investment risk and aggregate saving. Review of Economic Dynamics 10, 1-30.

Chamley, C., 1986. Optimal taxation of capital income in general equilibrium with infinite lives. Econometrica 54, 607-622.

Domar, E.D., Musgrave, R.S., 1944. Proportional income taxation and risk-taking. Quarterly Journal of Economics 58, 388-422.

Judd, K.L., 1985. Redistributive taxation in a simple perfect foresight model. Journal of Public Economics 28, 59-83.

Kanbur, S.M., 1981. Risk taking and taxation. Journal of Public Economics 15, 163-184.

Mirrlees, J.A., 1990. Taxing uncertain incomes. Oxford Economic Papers 42, 3445.

Moskowitz, T., Vissing-Jorgensen, A., 2002. The returns to entrepreneurial investment: A private equity premium puzzle? American Economic Review 92, 745-778.

Panousi, V., Papanikolaou, D., 2011. Investment, idiosyncratic risk, and ownership. Journal of Finance (forthcoming).

Panousi, V., 2012. Capital taxation with entrepreneurial risk. Federal Reserve Board mimeo.

Sandmo, A., 1977. Portfolio theory, asset demand and taxation: Comparative statics with many assets. Review of Economic Studies 44, 369-379.

Stiglitz, J.E., 1969. The effects of income, wealth, and capital gains taxation on risk-taking. Quarterly Journal of Economics 83, 263-283.

Varian, H.R., 1980. Redistributive taxation as social insurance. Journal of Public Economics 14, 49-68. 


\section{Appendix}

\subsection{The model with CRRA preferences}

In this section, we continue to assume that production is $A K$ and that there is no safe income, but we allow preferences to be CRRA, with $\theta=1 / \gamma \neq 1$. The only difference from the benchmark model is that the marginal propensity to consume out of wealth, $m_{t}$, will now not be equal to the discount rate, $\beta$, but will instead be characterized by an Euler equation. In this case, (7) becomes:

$$
\frac{d c_{t}^{i}}{c_{t}^{i}}=\left[\left(1-\tau_{t}\right) r-m_{t}\right] d t+\sigma\left(1-\tau_{t}\right) d z_{t}^{i}
$$

and (8) becomes:

$$
c_{t}^{i}=c_{0}^{i} \exp \left[\int_{0}^{t}\left(\left(1-\tau_{s}\right) r-m_{s}-\frac{1}{2} \sigma^{2}\left(1-\tau_{s}\right)^{2}\right) d s+\int_{0}^{t} \sigma\left(1-\tau_{s}\right) d z_{s}^{i}\right] .
$$

Since preferences are homothetic, individual consumption is log-normally distributed. Let $\mu_{c}$ and $\sigma_{c}$ denote the mean and variance of individual consumption, respectively. Taking logs in (22) gives:

$$
\ln c_{t}^{i}=\ln c_{0}^{i}+\int_{0}^{t}\left(\left(1-\tau_{s}\right) r-m_{s}-\frac{1}{2} \sigma^{2}\left(1-\tau_{s}\right)^{2}\right) d s+\int_{0}^{t} \sigma\left(1-\tau_{s}\right) d z_{s}^{i} \sim N\left(\mu_{c}, \sigma_{c}\right)
$$

where

$$
\mu_{c}=\ln c_{0}^{i}+\int_{0}^{t}\left(\left(1-\tau_{s}\right) r-m_{s}-\frac{1}{2} \sigma^{2}\left(1-\tau_{s}\right)^{2}\right) d s
$$

and

$$
\sigma_{c}^{2}=\int_{0}^{t} \sigma^{2}\left(1-\tau_{s}\right)^{2} d s
$$

With CRRA preferences, utility will also be log-normal:

$$
\ln u_{t}^{i}=\ln \left(\frac{1}{1-\gamma}\right)+(1-\gamma) \ln c_{t}^{i} \sim N\left(\mu_{u}, \sigma_{u}\right)
$$

where

$$
\mu_{u}=(1-\gamma) \mu_{c}+\ln (1-\gamma)
$$

and

$$
\sigma_{u}^{2}=(1-\gamma)^{2} \sigma_{c}^{2}
$$

The planner maximizes:

$$
V_{0}=E_{-1} \int_{0}^{\infty} e^{-\beta t} u\left(c_{t}^{i}\right) d t=\int_{0}^{\infty} e^{-\beta t} E_{-1}\left[u\left(c_{t}^{i}\right)\right] d t=\int_{0}^{\infty} e^{-\beta t} \exp \left\{\mu_{u}+\frac{1}{2} \sigma_{u}^{2} d t\right\}
$$


After some algebra, we can write the planner's objective as:

$$
V_{0}=\int_{0}^{\infty} e^{-\beta t} \frac{c_{0}^{i, 1-\gamma}}{1-\gamma} \exp \left\{\int_{0}^{t}\left[(1-\gamma) g\left(\tau_{s}\right)\right] d s\right\} d t
$$

where

$$
g\left(\tau_{s}\right)=\left(1-\tau_{s}\right) r-m_{s}\left(\tau_{s}\right)-\frac{\gamma}{2} \sigma^{2}\left(1-\tau_{s}\right)^{2}
$$

Note that $V_{0}$ is always increasing in $g\left(\tau_{s}\right)$, and that $\tau_{s}$ only enters $V_{0}$ through $g\left(\tau_{s}\right)$. Hence, by maximizing $g\left(\tau_{s}\right)$ with respect to $\tau_{s}$, we are actually maximizing $V_{0}$. More formally:

$$
\frac{d V_{0}}{d \tau_{s}}=\frac{d V_{0}}{d g\left(\tau_{s}\right)} \frac{d g\left(\tau_{s}\right)}{d \tau_{s}} \text { and } \frac{d V_{0}}{d \tau_{s}}=0 \text { iff } \frac{d g\left(\tau_{s}\right)}{d \tau_{s}}=0
$$

Taking the first order condition of $g\left(\tau_{s}\right)$ with respect to $\tau_{s}$ yields:

$$
-r-m_{s}^{\prime}\left(\tau_{s}\right)+\gamma \sigma^{2}\left(1-\tau_{s}\right)=0
$$

where $m_{s}^{\prime}\left(\tau_{s}\right)$ is the derivative of the marginal propensity to consume with respect to the tax, to be calculated from the Euler equation. Equation (33) defines the optimal tax. Note that we can write this equation as:

$$
\tau_{s}=1-\frac{r+m_{s}^{\prime}\left(\tau_{s}\right)}{\gamma \sigma^{2}}<1
$$

and we need $\gamma \sigma^{2}>r+m_{s}^{\prime}\left(\tau_{s}\right)$ for a positive optimal tax. For the optimal tax to be an equilibrium, it needs to clear the bond market, which means that the optimal tax will be an equilibrium if and only if $R_{t}=m_{t}^{\prime}\left(\tau_{t}\right)$. If the marginal propensity to consume does not depend on the tax (as in the case of logarithmic preferences, where $m_{t}=\beta$ ), then $R_{t}=m_{t}^{\prime}\left(\tau_{t}\right)=0$ in equilibrium of the optimal tax, as we found in the previous section. Note also that, in general, the optimal tax will not be constant, unless the marginal propensity to consume is constant, as the case of logarithmic preferences. 